\title{
On the Role of Bulk Properties and Fuel Species on the Burning Dynamics of Pine Forest Litters
}

\author{
ALBERT SIMEONI ${ }^{1}$, PAULINE BARTOLI ${ }^{2,3}$, JOSÉ LUIS TORERO ${ }^{2}$, and PAUL-ANTOINE \\ SANTONI ${ }^{3}$ \\ ${ }^{1}$ Department of Fire Protection Engineering \\ Worcester Polytechnic Institute \\ Worcester, MA, USA \\ ${ }^{2}$ Centre for Fire Safety Engineering \\ University of Edinburgh \\ Edinburgh, UK \\ ${ }^{3}$ SPE - UMR CNRS 6134 \\ University of Corsica \\ Corte, France
}

\begin{abstract}
This work aims to characterize pine needles as a fuel for a better understanding of the burning dynamics of forest floor fuels in wildland fires. Three Mediterranean species of pine have been studied: Pinus halepensis, Pinus pinaster and Pinus laricio. These species have been chosen because they present close but slightly different physical and chemical properties. The study focuses on the influence of the bulk and particle properties on the burning dynamics of pine needles litters. The permeability of the porous fuel beds as well as the physical and chemical characteristics of each fuel have been determined experimentally. The combustion experiments were performed using the FM Global Fire Propagation Apparatus. The heat release rate estimation was done by using oxygen consumption calorimetry with a correction of the energy constant since the composition of the fuels was known. Two kinds of sample holders were used, one with holes to allow different air flow rates to pass through the fuel sample and one blocked to stop the flow at the bottom and the sides of the fuel sample. The different air flow rates were natural convection and different rates of forced flows. A mean value of the energy released during the flaming stage per unit mass loss can be determined for all species under the different flow conditions. This energy is related to the fireline intensity, which is an important quantity for foresters, and firefighters that allows them to evaluate the fire impact and the means which are necessary to fight a fire. Permeability appears to be an important parameter when analyzing the combustion dynamics of highly porous forest fuel beds. The energy released during flaming depends greatly on permeability but for the same permeability, the fuel species have an influence on the burning dynamics.
\end{abstract}

KEYWORDS: wildfires, porous fuel, heat release rate, burning dynamics, driving parameters.

\section{NOMENCLATURE LISTING}

$\begin{array}{llll}a & \text { expansion factor } & \Delta H_{c} & \text { heat of combustion }(\mathrm{kJ} / \mathrm{kg}) \\ E & \text { calorimetric constant }(\mathrm{MJ} / \mathrm{kg}) & \phi & \text { depletion factor } \\ K & \text { permeability }\left(\mathrm{m}^{2}\right) & \rho & \text { density }\left(\mathrm{kg} / \mathrm{m}^{3}\right) \\ m & \text { mass }(\mathrm{kg}) & \sigma & \text { surface-to-volume ratio }\left(\mathrm{m}^{-1}\right) \\ \dot{m} & \text { mass flow rate }(\mathrm{kg} / \mathrm{s}) & \text { subscripts } \\ M & \text { molar mass }(\mathrm{g}) & a & \text { air } \\ n & \text { number of moles }(\mathrm{mole}) & e & \text { exhaust } \\ \dot{q} & \text { heat release rate }(\mathrm{kW}) & s & \text { sample } \\ V & \text { volume }\left(\mathrm{m}^{3}\right) & \text { superscripts } \\ X & \text { mass fraction } & \text { o } & \text { before combustion } \\ \mathbf{G r e e k} & & A & \text { analyzers } \\ \alpha & \text { volume fraction } & * & \text { bulk } \\ \delta & \text { mean free path of radiation }(\mathrm{m}) & & \end{array}$




\section{INTRODUCTION}

Modeling has become an essential tool in forest fire research and is now a crucial instrument in the study of risk mapping and fire propagation, as well as forest management strategies. Fire behavior depends upon a number of interrelated factors and mechanisms, which are not totally understood yet. How wildland fuels burn and what parameters have the greatest influence over the combustion process are still questions to be addressed. Modelers need to know these parameters, as well as they need to use simple laws to describe them.

Pine needles present a clear fire hazard in pine forests by providing a continuous fuel matrix across the forest floor. Although crown fires usually show the most destructive behavior and contribute to wildland fire intensity, most of the time a forest fire presents itself as a surface fire. Wildland fire ignition mainly occurs in the fuel located on the ground and this fuel sustains fire spread to a great extent [1]. In a ground fire, the flame front propagates through a layer of dead fuel on the forest floor. There is a flow of air and gaseous combustion products inside the layer, which has an influence on the combustion dynamics. Some tools, which have been developed in older and more mature fields of combustion and fire safety, can be applied to understand the dynamics of wildfire spread. For instance, oxygen consumption calorimetry [2] has been and is still applied with great success in the fire safety community. The heat release rate (HRR) of a material when subject to fire is in many instances the most important variable in fire hazard assessment as it serves to define parameters such as entrainment for fire plumes and flame geometry for open fires [3]. This quantity is related to the fire-line intensity [4], which is an important quantity for foresters and firefighters that allow them to evaluate the fire impact and the means to use to fight a fire. The fire-line intensity is defined as the rate of heat released by meter of fire front. It can be derived either from the fire rate of spread and the mass loss [4] or from the length of flames [5]. The fire-line intensity of a spreading fire is equal to the HRR divided by the surface of the sample and multiplied by the depth of the fire front [6]. The fire-line intensity is then related to the HRR and to the flaming stage part of the combustion of vegetation. It is thus assumed that a better understanding of the dynamics of heat release during the combustion of fuel samples will allow better estimating of the fire-line intensity.

Previous studies started the effort of using calorimetric tools to better understand the burning of wildland fuels $[7,8]$. The results showed the applicability and usefulness of calorimetry for this purpose. The test conditions allowed the internal porous fuel bed characteristics to be examined. The results indicated that the transport processes inside the fuel bed have a significant impact on the combustion dynamics within the porous bed. The porous aspect of wildland fuel has been described since the first versions of wildfire spread models were developed [9]. However, many questions are still unanswered, particularly regarding the influence of particle and bulk properties on the burning dynamics of forest fuels. The work described in this paper presents a further step in this direction. It aims to correlate the burning dynamics with a few parameters relevant to forest fire research (permeability, surface-to-volume ratio, porosity, elementary analysis and low heating value) and be useful in fire spread models. The relevant parameters must be easy to estimate or to measure with dedicated experiments.

The work has been conducted as follows: First, the use of oxygen consumption calorimetry has been improved by a complete characterization of the fuels and a calculation of the oxygen consumption constant for each fuel species. Using this value instead of the average one improves the HRR calculation uncertainty [10] and allows a better analysis of close results for different species. Then, the variation of the mean HRR during flaming has been studied as a function of the flow, the permeability, the free mean path of radiation and the fuel species.

\section{SAMPLES AND EXPERIMENTAL DEVICE}

\section{Samples}

Three fuels have been studied. They were made with porous samples of pine needles beds from three different species, namely: Pinus pinaster $(\mathrm{Pp})$, Pinus halepensis $(\mathrm{Ph})$ and Pinus laricio $(\mathrm{Pl})$. The samples were collected from the top of forest floor litters in the Mediterranean (Corsica, France and Savona, Italy). Each species was collected at the same location for the whole duration of the study. The pine needle beds were cleaned of the other particles that could affect the repeatability of the experiments. The needles were dead and not conditioned prior to testing. Their moisture levels have been determined by oven drying of a 
sample for $24 \mathrm{~h}$ at $60{ }^{\circ} \mathrm{C}$. The percentage of moisture content of the fuel samples ranged between $5 \%$ and $7 \%$.

The fuel species present different characteristics such as surface-to-volume ratio, density and chemical composition. Since those characteristics can vary also for a given species according to the location [11,12], a proper characterization of those fuels has been made instead of using classical literature values in order to improve the precision and improve the analysis. Their surface to volume ratios and their densities have been determined following the method developed by the INRA [11]. The results are given in Table 1. They are noticeably different from one species to the other, Pinus halepensis has the highest surface-to-volume ratio, followed by Pinus laricio and then Pinus pinaster. The density allows estimating the volume fraction for a given mass load and a given volume of fuel. The surface-to-volume ratio and fuel volume fraction are the two mains parameters that are used in detailed physical models to describe the influence of fuel species on the combustion dynamics [13].

Table 1. Surface to volume ratios and densities of the three pine needle species.

\begin{tabular}{|l|c|c|}
\hline Species & $\begin{array}{c}\left.\text { Surface to volume ratio }{\left(\mathbf{m}^{-1}\right.}^{-1}\right) \\
\text { (relative uncertainty) }\end{array}$ & $\begin{array}{c}\text { Density }\left(\mathbf{k g} \cdot \mathbf{~ m}^{-3}\right) \\
\text { (relative uncertainty) }\end{array}$ \\
\hline $\mathrm{Ph}$ & $7377(2.4 \%)$ & $789(2.4 \%)$ \\
\hline $\mathrm{Pl}$ & $4360(3.3 \%)$ & $485(8.1 \%)$ \\
\hline $\mathrm{Pp}$ & $3057(1.3 \%)$ & $511(6.6 \%)$ \\
\hline
\end{tabular}

A chemical characterization has also been conducted for the three species. The low heating values (determined in a bomb calorimeter) and their elemental analysis are given in Table 2. The three species have similar low heating values as the variation between the species is less than $5 \%$. The elemental analysis provides similar values too: less than $3 \%$ difference for $\mathrm{C}, \mathrm{H}$ and $\mathrm{O}$, the variation in $\mathrm{N}$ is more important, with Pinus halepensis having the highest concentration. Overall, the main difference between the species is due to their geometry and particularly to their surface-to-volume ratios.

Table 2. Elemental analysis (mass units) and low heating value of the three forest fuels.

\begin{tabular}{|c|c|c|c|c|c|}
\hline Species & $\mathbf{C}$ & $\mathbf{H}$ & $\mathbf{O}$ & $\mathbf{N}$ & $\mathbf{L H V}\left(\mathbf{k J \cdot \mathbf { g } ^ { - 1 }}\right)$ \\
\hline $\mathrm{Ph}$ & 49.17 & 6.75 & 39.14 & 1.19 & 21.20 \\
\hline $\mathrm{Pl}$ & 50.39 & 6.72 & 39.65 & 0.30 & 21.33 \\
\hline $\mathrm{Pp}$ & 49.87 & 6.72 & 40.16 & 0.26 & 20.41 \\
\hline
\end{tabular}

\section{Permeability}

Forest floor fuel beds are extremely porous with porosities around 0.05 for pine needle litters [14]. Thus, the flow of air and gaseous combustion products inside them greatly influences their combustion dynamics. The interaction between the solid fuel and the gas flowing through the porous fuel is represented by the bed permeability, as long as the flow is laminar. This quantity depends on many fuel properties such as the surface-to-volume ratio, the roughness of the particle's surface and the fuel bed porosity among others. There is no simple relationship between permeability and one of these properties taken alone [15]. Permeability (or drag forces for turbulent flows) can be included as model parameters to take into account the gas/solid interaction in detailed physical models $[13,16]$.

The permeability $(K)$ of reconstructed forest floor fuel beds have been estimated for the three pine species and for different levels of compactness. A simple and robust experiment has been designed based on Darcy's law. The experimental set-up consisted of three components: an electric fan connected with a speed controller, a contraction chamber and a work module which consisted of a clear PMMA tube with a total length of $800 \mathrm{~mm}$. Wire mesh was placed at the entrance of the tube in order to hold the needles in place. Static pressure taps were connected along the length of the tube at regular intervals. A Kimo® thermo anemometer with hotwire was used to measure the exit velocity of the air flow. The pressure taps and the hotwire anemometer were connected to a Kimo ${ }^{\circledR}$ AMI 301 micro-manometer. It was assumed that the drop in pressure would be linear along the length of the pine needle bed; however, for confirmation of 
this assumption, the pressure was measured along the length in every test performed. This also allowed for a further check of the homogeneity of the pine needle bed. A basic layout of the experimental set-up is given in Fig. 1.

The values of permeability have been determined by using Darcy's law for low flow velocities that ranged between $0.2 \mathrm{~m} . \mathrm{s}^{-1}$ and $1 \mathrm{~m} \cdot \mathrm{s}^{-1}$, depending on the considered species and compactness. These velocities correspond to a laminar flow through the pine needles and the experimental results displayed a linear relationship between pressure drop and flow velocity. The experimental set-up did not allow measurement of the permeability for Pinus halepensis beds with a low compactness (equivalent to a $10 \mathrm{~g}$ sample in the calorimetry experiments, see next section) since the needles were too small to stay homogeneously distributed and collapsed in the tube at higher compactness. The value of the permeability for low fuel loads were extrapolated from the permeability obtained with denser fuels.

Experimental results for Pinus halepensis and a load equivalent to a $20 \mathrm{~g}$ sample in the calorimetry experiments (see next section) are given as an example in Fig. 2. The pressure drop inside the porous fuel bed is proportional to the imposed flow velocity. The permeability $K$ is then deduced from the slope.

The results for the permeability experiments are given in Table 3 . The fuel bed permeability depends on the compactness of the bed. Indeed, it decreases with the mass of the fuel sample used in the calorimetry experiments as all the fuel samples have the same volume. It also depends on the other geometrical (surface-to-volume ratio and shape) and physical (density and roughness) properties of the pine needles and the same volume fraction will not provide the same permeability for different fuel species.

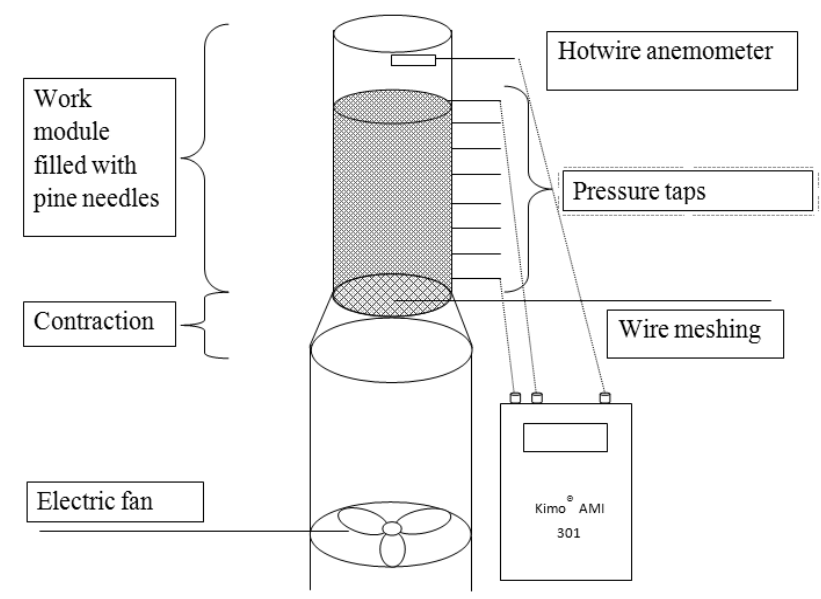

Fig. 1. Layout of the permeability experimental set-up.

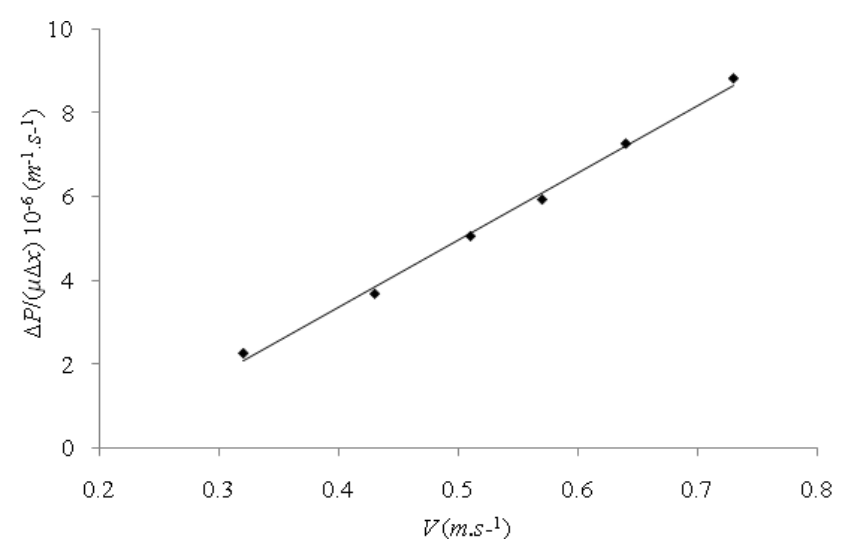

Fig. 2. Pinus halepensis pressure drop per unit length as a function of flow velocity for a fuel load equivalent to a $20 \mathrm{~g}$ sample. 
Table 3. Permeability $\left(\times 10^{-7} \mathrm{~m}^{2}\right)$ of samples for the three pine species and the different mass values used in the calorimetry experiments.

\begin{tabular}{|c|c|c|c|c|}
\hline Sample mass (g) & $\mathbf{1 0}$ & $\mathbf{1 5}$ & $\mathbf{2 0}$ & $\mathbf{2 5}$ \\
\hline $\mathrm{Ph}$ & - & 0.906 & 0.571 & 0.303 \\
\hline $\mathrm{Pp}$ & 2.649 & 1.014 & 0.640 & 0.397 \\
\hline $\mathrm{Pl}$ & 3.144 & 1.447 & 0.892 & 0.448 \\
\hline
\end{tabular}

\section{Calorimetric Analysis}

The experiments presented in this paper were conducted using the FM Global fire propagation apparatus (FPA) [17]. This device allows the measurement of the energy released by the combustion of a material by the means of oxygen consumption calorimetry. The fuel sample is subjected to a radiative heat flux, and a piloted ignition source is provided. The relevance of this procedure for wildland fire studies is that small samples can be subjected to high radiative heat fluxes at the same order of magnitude as the fluxes encountered in the field. For this study, the radiative heat flux imposed on the sample was of $25 \mathrm{~kW} \cdot \mathrm{m}^{-2}$. This heat flux was chosen because it is characteristic of surface fires in pine needle beds [18] and because it allowed ignition times and flame durations to be obtained, which were suitable for the comparison between the three species. Higher heat fluxes led to very short ignition and combustion times for the experimental conditions considered in this study. The infrared heaters were not shut down after ignition but remained switched on during the whole test. The mass loss rate was measured and the exhaust gases were analyzed for composition, temperature, optical obscuration and flow speed with a Pitot tube.

The FPA allows both natural convection and forced gas flow rate through the fuel bed. Specific sample holders were used for the experiments [7]. The sample holders were circular baskets, made of stainless steel, with holes on all the surfaces (sides and bottom), to allow airflow to pass through the bed of pine needles. They all had the same volume. Two different percentage openings have been tested: $0 \%$ (one basket lined with aluminum foil), and $63 \%$. The baskets were designed to allow the airflow to enter the sample from all directions (63\% opening) as in natural fuel beds or to block it ( $0 \%$ opening) to remove its influence [4].

The sample holders fitted inside the combustion chamber, which is cylindrical, and sat on a load cell. Four experimental factors were tested: the fuel species, the mass of combustible (between $10 \mathrm{~g}$ and $20 \mathrm{~g}$ ), the basket opening and finally the convection conditions: natural flow (NF), low flow of $100 \mathrm{~L} \cdot \mathrm{min}^{-1}(\mathrm{LF})$, and high flow of $200 \mathrm{~L} \cdot \mathrm{min}^{-1}$ (HF). The accurate value of the airflow through the fuel bed samples was not directly measured, as the sample holder was a bit smaller than the combustion chamber. It was estimated, by particle image velocity of a non-reacting flow, that $25-35 \%$ of the flow went through the sample holder, depending on the fuel species when using the $63 \%$ opening baskets under HF conditions baskets [7]. Each test condition was repeated between three and six times. This study aims to provide a better understanding of the burning dynamics of forest fuel porous beds and qualitative results are sufficient in this context. Quantitative results will be necessary to develop sub-models to include in physical forest fire spread models and any future study will be based on the conclusions provided by the qualitative study.

\section{CALORIMETRIC CALCULATIONS}

The HRR will be used in the following to compare the burning dynamics of the three pine species. However, the species have similar chemical properties (see Table 2) and can provide similar results. It is therefore necessary to obtain an accurate estimation of the HRR under the different flow conditions. A procedure is proposed here to improve the estimation of the calorimetric constants for each fuel species, leading to an improvement of the HRR estimation.

Oxygen consumption calorimetry (OC) comes from the observation made that, for a large number of fuels, the energy released per unit mass of oxygen consumed can be considered as a constant: Huggett's constant $(E)$, which is equal to $13.1 \mathrm{MJ} \cdot \mathrm{kg}^{-1}$ of oxygen consumed [19]. The OC principle expresses HRR as:

$\dot{q}=E\left(\dot{m}_{O_{2}}^{\circ}-\dot{m}_{O_{2}}\right)$ 
Equation 1 has been developed for various applications, depending on the measured quantities [2]. The oxygen molar fraction must be measured; to improve the accuracy, the molar fraction of $\mathrm{CO}_{2}, \mathrm{CO}$ and $\mathrm{H}_{2} \mathrm{O}$ must be measured as well [20]. Janssens [2] proposed practical equations for various gas analyzer configurations. From the data provided by the FPA, the HRR can be obtained as follow:

$\dot{q}=\left[E \phi-\left(E_{C O}-E\right) \frac{1-\phi}{2} \frac{X_{C O}^{A}}{X_{O_{2}}^{A}}\right] \frac{\dot{m}_{e}}{1+\phi(a-1)} \frac{M_{O_{2}}}{M_{a}}\left(1-X_{H_{2} O}^{\circ}\right) X_{O_{2}}^{A^{\circ}}$

The HRR is not obtained directly but is computed from many variables. Each variable has a corresponding uncertainty which reflects in the mathematical function giving the HRR according to the law of error propagation [21]. Those uncertainties are of two kinds: due to experimental measurements (analyzers' uncertainties) and due to the hypotheses used $[20,22]$. It has been shown in previous studies on oxygen consumption calorimetry uncertainty that the oxygen consumption calorimetry energy constant $E$ is one of the most important factors contributing to the uncertainty [20,22]. The variation in HRR due to the variation in $E$ is given by:

$\delta \dot{q}=\frac{\partial \dot{q}}{\partial E} \delta E$

where

$$
\frac{\delta \dot{q}}{\delta E}=\left[\phi+\frac{1-\phi}{2} \frac{X_{C O}^{A}}{X_{O_{2}}^{A}}\right] \frac{\dot{m}_{e}}{1+\phi(a-1)} \frac{M_{O_{2}}}{M_{a}}\left(1-X_{H_{2} O}^{\circ}\right) X_{O_{2}}^{A^{\circ}}
$$

When the fuel composition is known, a more accurate value for $E$ can be determined [10,23]. The stoichiometric chemical equation for a complete oxidation of a compound $\mathrm{C}_{x} \mathrm{H}_{y} \mathrm{O}_{z}$ is given by:

$$
C_{x} H_{y} O_{z}+\left(x+\frac{y}{4}-\frac{z}{2}\right)\left(O_{2}+3.76 N_{2}\right) \rightarrow x C O_{2}+\frac{y}{2} H_{2} O+3.76\left(x+\frac{y}{4}-\frac{z}{2}\right) N_{2}
$$

The oxygen consumption calorimetry energy constants can be estimated from the fuels' elemental analysis and low heating values (LHV). Following the assumption of complete oxidation (valid since the experiments conducted in this work are well-ventilated), the energy constants can be estimated from the stoichiometric chemical equation as follow [10,23]:

$$
E_{s t}=\frac{\Delta H_{c, \text { fuel }} M_{\text {fuel }}}{n_{O_{2}} M_{O_{2}}}
$$

with:

$$
n_{O_{2}}=\left(x+\frac{y}{4}-\frac{z}{2}\right)
$$

This calculation has been made for the three pine needle species from the values given in Table 2 . The results are provided in Table 4. The variation from the standard $E$ value $(\delta E)$ is an increase by $6.7 \%$ for Pinus pinaster, $10.1 \%$ for Pinus laricio and $11.3 \%$ for Pinus halepensis. According to Eq. 3, this variation will affect HRR calculations.

Pinus halepensis HRR in high flow conditions obtained from both the average and the calculated values of $E$, as well as the variation in HRR calculated from Eqs. 3 and 4 are given as an example in Fig. 3. Using the specific $E$ values for each fuel instead of the average ones improves the precision on the HRR calculation. The HRR is underestimated by the use of the average constant for the three species. 
Figure 4 shows that using the same energy constant for different fuel species can lead to errors since the HRR which was calculated using the average constant is not underestimated in the same proportion according to the species. In the present study, those constants are used to determine the HRR during both the flaming and smoldering stages of combustion. Previous studies have shown that pyrolysis gases and char have different heat of combustion values [12,24]. However, these new constants present an improvement of the HRR estimation accuracy and allow the differences in calorific power between the species to be taken into account. The improvement is certainly greater under forced flow conditions when both flaming and smoldering occur simultaneously [7]. A way to further improve the HRR estimation would be to attribute different constants for flaming and smoldering but the mass loss rate due to each process would need to be known for every condition.

Table 4. Oxygen consumption calorimetry energy constants for the three pine species.

\begin{tabular}{|l|c|c|}
\hline Species & $\boldsymbol{n}_{\boldsymbol{O}_{\mathbf{2}}}(\mathbf{m o l e})$ & $\boldsymbol{E}_{\boldsymbol{O}_{\mathbf{2}}}\left(\mathbf{M J} \cdot \mathbf{k g}^{-\mathbf{1}}\right)$ \\
\hline $\mathrm{Ph}$ & 4.545 & 14.58 \\
\hline $\mathrm{Pl}$ & 4.623 & 14.42 \\
\hline $\mathrm{Pp}$ & 4.561 & 13.98 \\
\hline
\end{tabular}

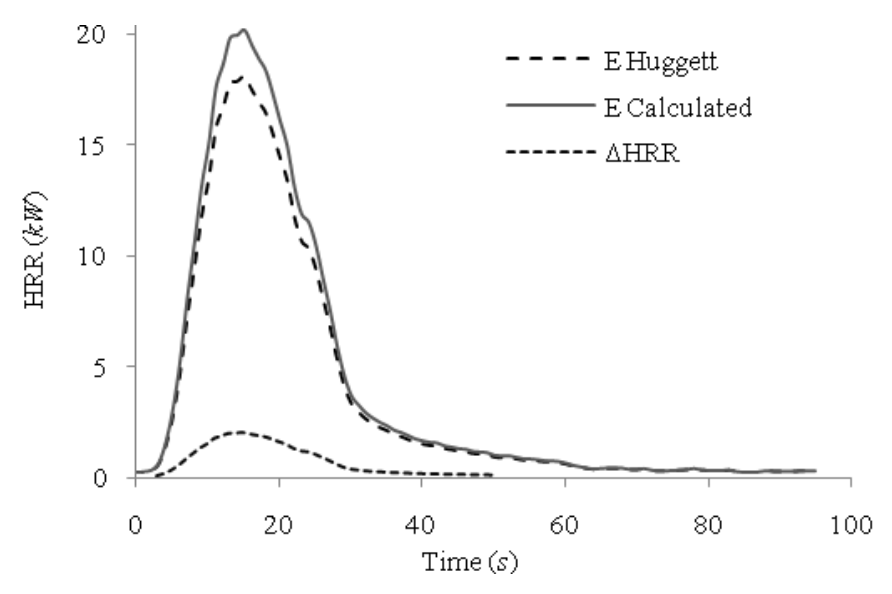

Fig. 3. Pinus halepensis HRR using $E$ average, $E$ calculated and $\triangle \mathrm{HRR}$ for a $63 \%$ opening basket and HF.

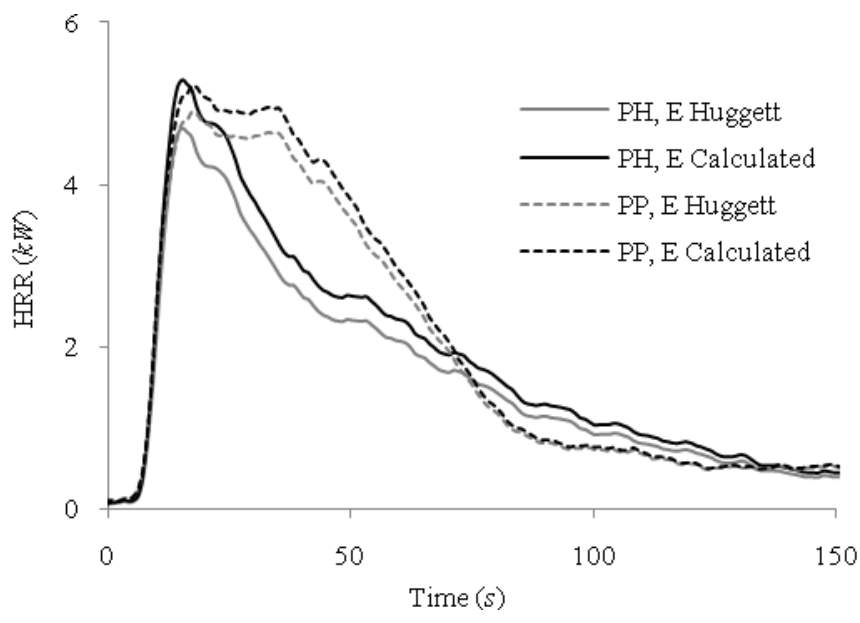

Fig. 4. Pinus halepensis $15 \mathrm{~g}$ and Pinus pinaster $20 \mathrm{~g}$ HRR using $E$ average and $E$ calculated for the closed basket and NF. 


\section{BULK EFFECTS}

Previous studies have shown that flow conditions through the porous fuel bed and fuel species properties have both an influence on the burning dynamics of pine needles and present cross-interactions $[7,8]$. However, these studies did not discriminate these effects and did not take into account one of the main bulk properties of porous fuel beds, which is permeability. The different parameters playing a role on the oxygen supply inside the fuel bed (i.e. flow magnitude and fuel bed permeability) are studied in this section. The fuel species properties are studied in the next section.

\section{Variation of Flow}

The oxygen supply inside the porous fuel bed is one of the main parameters driving the combustion dynamic and it depends on the flow magnitude inside the porous fuel bed. Figure 5 presents the HRR curves for Pinus halepensis. In general, the flow is increasing the HRR during flaming and shortening the flame duration. Under no flow conditions, the HRR increases from the closed basket (0NF) to the open one (63NF). The closed basket involves different flow conditions than the open one as the air can only come from the top of the fuel sample. It is consumed at the surface of the bed by the flame and the superficial char. Thus, the reaction is slower with lower observed flames and a propagation of the pyrolysis front from the top to the bottom of the bed during combustion. With the open basket, the air can come inside the porous medium from both the sides and the bottom of the fuel sample. If one considers the area under the curves, more energy is released when natural convection is allowed through the basket. This result is consistent with the total mass loss that is higher for the open basket than for the closed one. Indeed, due to the flow limitation mechanisms previously described, some charred needles were remaining at the bottom of the closed baskets after combustion. When the flow is forced through the basket (63LF and 63HF), the HRR is enhanced, leading to a higher peak HRR and shorter combustion times. The flaming and smoldering stages become simultaneous as more oxygen is made available for heterogeneous combustion inside the fuel bed [7].

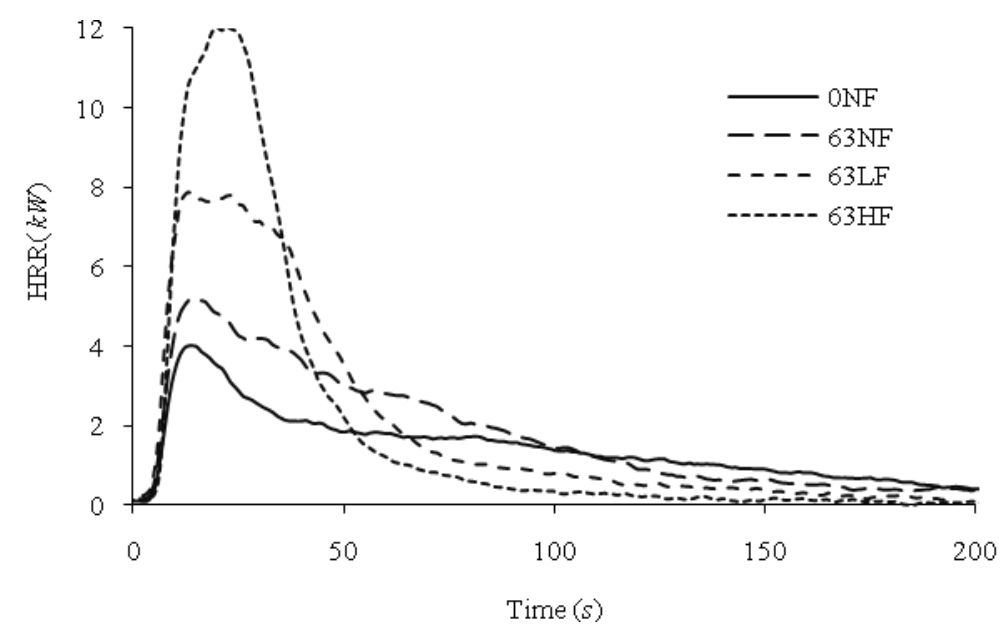

Fig. 5. HRR for Pinus halepensis as a function of the flow with a bed permeability of $K=1 \times 10^{-7} \mathrm{~m}^{2}$ and a $20 \mathrm{~g}$ mass.

In the current experiments, the air supply has been artificially controlled by the basket opening and the forced flow. Under actual fire conditions, the oxygen supply will be controlled by the permeability of the porous medium and the flow magnitude inside the fuel bed.

\section{Variation of Fuel Bed Permeability}

The permeability is a function of the roughness, the shape and the surface-to-volume ratio of the needles, as well as the fuel volume fraction of the solid phase. Using different pine needle species will change the properties of the fuel beds and will not allow an understanding of which parameter plays a prevalent role in the combustion dynamics [7,8]. The permeability experiments have been performed with Pinus halepensis for four different permeability values and for all the flow conditions. To ensure that the flow was kept laminar, the Reynolds number was estimated for each condition providing values between 0.8 and 4.4 for 
HF conditions, depending on the fuel species. The study has been focused on the flaming stage. Indeed, if one does not consider firebrands, the flaming stage is responsible of the fire spread and the remaining char burns slowly far from the fire front.

The peak HRR duration is very short due to the small size of the baskets which favors a complete burning of the fuel sample in a short time (less than $30 \mathrm{~s}$ for flaming when a high flow is imposed). Thus, it is not representative of the natural phenomenon and the results are presented in terms of mean heat release rates on the flaming stage divided by mass loss the of fuel during the flaming stage $\left(\mathrm{kW} \cdot \mathrm{g}^{-1}\right)$. This quantity is also closer to the definition of the fire-line intensity used for wildfires [4,5].

Figure 6 shows the results obtained for Pinus halepensis with four different values of the fuel bed permeability. There is no experimental data for the higher permeability with high flow (HF) since it was impossible to get a piloted ignition due to the dilution of the pyrolysis gases around the pilot flame. Some results are quite scattered since the ignition time was quite sensitive to the surrounding flow. For a given condition (basket and flow) the energy released during the combustion of the porous fuel bed increases with its permeability. Indeed, the oxygen supply inside the porous fuel bed is enhanced when the permeability is increasing. It can also be seen that the flow influence increases with the permeability as the slopes of the curves increase with the permeability. Porous fuel bed permeability influence on forest fuel combustion dynamics appears to be important and should be taken into account when modeling fire spread in such fuel beds.

The HF values show an inflexion in the increase tendency. It looks like that the flow enhancement of the burning is reaching a limit. However, Fig. 5 shows that the HRR is still increasing greatly between LF and HF. A misleading conclusion could be reached because of analyzing only a mean value. It highlights the limitations in the use of mean values like the fire-line intensity in wildfires. The mean values can lead to an underestimation of the peak of energy that is released during a fire. Thus the mean values have to be used in conjunction with other instantaneous quantities to fully understand the burning dynamics of a fire.

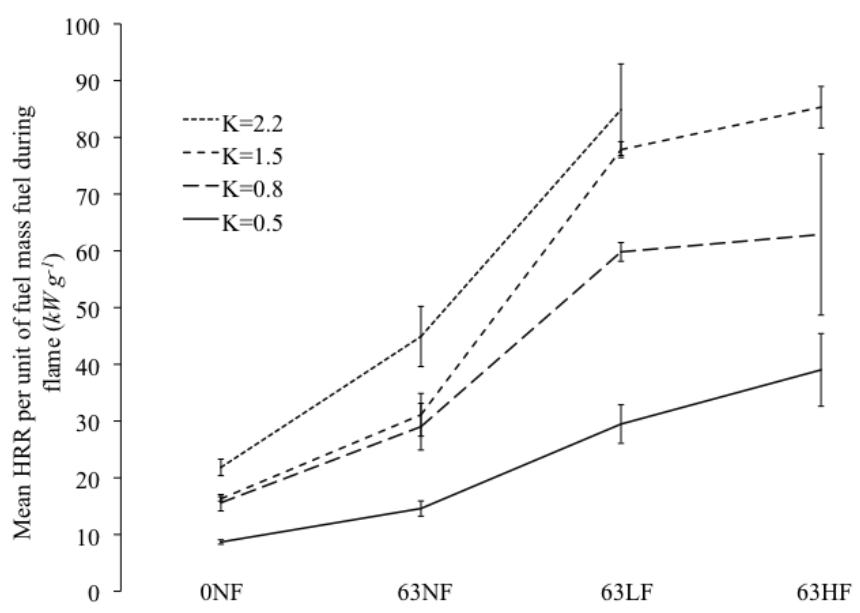

Fig. 6. Pinus halepensis mean HRR per unit of fuel mass during the flame as a function of the permeability $K\left(\times 10^{-7} \mathrm{~m}^{2}\right)$.

\section{Free Mean Path of Radiation}

Another bulk property of the fuel beds is the mean free path of radiation. It is calculated from the standard formula [25]:

$\delta=\frac{4}{\alpha \sigma}$

with $\alpha$ estimated as:

$\alpha=\frac{\rho^{*}}{\rho}=\frac{m_{s}}{V_{s} \rho}$ 
The values of $\alpha, \sigma$ and $\rho$ can be found in Table 1 .

The mean free path of radiation for each experimental condition is given in Table 5. As the surface-tovolume ratio is constant for the same species, the mean free path of radiation increases with the fuel volume fraction, that is to say compactness of the fuel bed. For the same species, the compactness is also directly related to the permeability. The increase of the HRR with permeability for a given flow condition can be explained by the increase of the free mean path of radiation (see Table 5). An increase in $\delta$ induces an increased in-depth heating of the fuel sample. As more fuel is heated up, the pyrolysis rate and the burning of the samples are enhanced.

Table 5. Free mean path of radiation $(\mathrm{mm})$.

\begin{tabular}{|c|c|c|c|c|}
\hline $\boldsymbol{K}\left(\mathbf{\times 1 \mathbf { 1 0 } ^ { - \mathbf { 7 } } \mathbf { ~ m } ^ { \mathbf { 2 } } )}\right.$ & $\mathbf{2 . 2}$ & $\mathbf{1 . 5}$ & $\mathbf{0 . 8}$ & $\mathbf{0 . 5}$ \\
\hline $\mathrm{Ph}$ & 18.7 & 15.5 & 12.4 & 9.3 \\
\hline $\mathrm{Pl}$ & 17.6 & 14.9 & 10.7 & - \\
\hline $\mathrm{Pp}$ & 29.2 & 19.4 & 14.7 & - \\
\hline
\end{tabular}

\section{FUEL SPECIES}

The three species have different geometrical and chemical characteristics (see Tables 1 to 3 ) as well as having different values of permeability for the same sample mass. To get free of the influence of the fuel beds on the flow and then focus on the influence of the physical and chemical characteristics of the fuel beds on the burning dynamics, a set of experiments has been performed with the same permeability of $1.5 \times 10^{-7} \mathrm{~m}^{2}$ for the three species. The mass of combustibles used has been estimated by interpolation of the permeability data (cf. Table 3) being $12 \mathrm{~g}, 13 \mathrm{~g}$ and $15 \mathrm{~g}$ for Pinus halepensis, Pinus laricio and Pinus pinaster, respectively.

The three species present different combustion dynamics with different flame durations and mass losses during flaming (see Figs. 7 and 8). These two quantities increase with the surface-to-volume ratio of the species (see Table 1): Pinus halepensis, which has the highest surface-to-volume ratio provides the longest flame duration and the highest percentage of mass loss during flaming, followed by Pinus laricio and Pinus pinaster. The tendencies can be partially explained by the mean path of radiation as Pinus pinaster has the highest value (see Table 5) and is burning the fastest as shown in Fig. 7. However, Pinus halepensis and Pinus laricio have similar values that vary opposite to the experimental tendency. It should be noticed that the evaluation of $\delta$ (Eq. 8) is based on the assumption of cylindrical shapes for the needles [25]. This is not the case and some discrepancies between the theoretical value obtained by Eq. 8 and the measured value have already been noticed [26]. Thus, even if Eq. 8 can provide a good estimation of $\delta$ for very different fuels (30\% variation between Pinus pinaster and Pinus laricio), more resolution is needed for similar fuels as Pinus halepensis and Pinus laricio (3\% variation) and a better estimation of $\delta$ is necessary before drawing further conclusions. Under high flow conditions (63HF), the tendency observed for no flow (NF) changes for Pinus pinaster and it is explained in the following paragraphs.

To study the influence of species on the heat released per unit mass of combustible during the flame, the presented results have been reduced as previously and are presented in Fig. 9. The three species have similar but different chemical compositions. Those differences leads to different oxygen consumption energy constants and are now taken into account for calorimetric calculations (has detailed previously), which was not the case in previous studies [8]. As stated before, the use of energy constants specific to each species instead of average energy constants allows accurate tendencies to be obtained to make a better comparison between species.

Figure 9 shows that under the no flow condition, the heat released by the three species during flaming increases when more oxygen is allowed to pass through the fuel bed sample. Pinus halepensis and Pinus laricio display similar values. Pinus pinaster seems to be more 'energetic' than the two others species but as it has the lowest lower heating value, the chemical properties of the species cannot explain this result. The difference between species may be due to the radiative transfer inside the fuel bed as described in the previous section - Pinus pinaster having the highest $\delta$ - or due to the fact that this species is releasing the highest amount of flammable gases during pyrolysis [12]. Under flow conditions, the tendency is changing. 
For Pinus halepensis and Pinus laricio the heat released per unit mass goes on increasing with the flow. Pinus halepensis is more influenced by the flow than Pinus laricio, maybe because of its high surface-tovolume ratio that allows more oxygen contact at the surface of the solid for pyrolysis and heterogeneous reactions. However, there is an inflexion for the two species when a high flow (HF) is applied. For Pinus pinaster, the mean HRR per unit mass is decreasing.

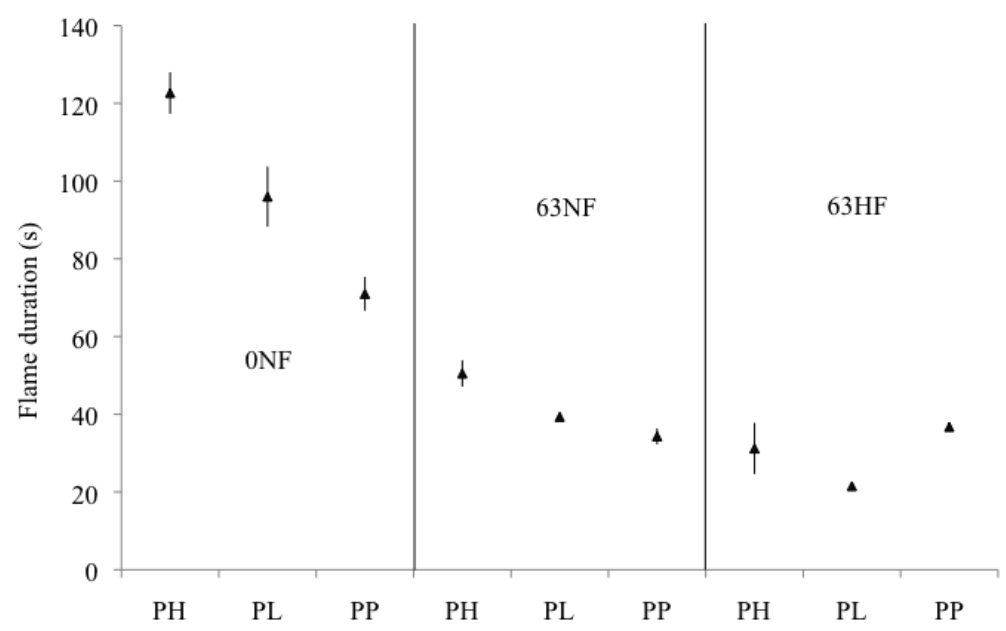

Fig. 7. Flame duration for the three species as a function of the flow condition, $K=1.5 \times 10^{-7} \mathrm{~m}^{2}$.

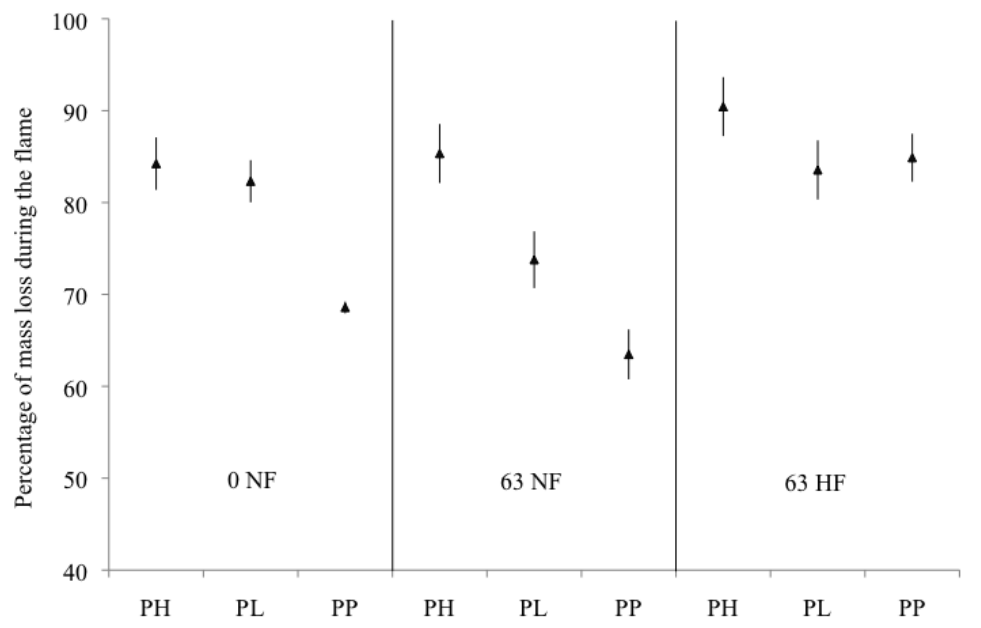

Fig. 8. Percentage of mass loss during the flame for the three species, $K=1.5 \times 10^{-7} \mathrm{~m}^{2}$.

Figure 10 shows that there is a real limiting effect for Pinus pinaster. It seems that the flow enhancement of the combustion reaches a limit and no more oxygen is necessary to improve the efficiency of the reaction. This is particularly true with the well-ventilated combustion in this study. Some limiting effects are even likely to occur when further increasing the flow, such as the dilution of the pyrolysis gases or the cooling of the solid phase. Figure 10 shows that for a high flow (HF), the first increase in the HRR curve is less steep than for a low flow (LF). The reaction is slowed down and the energy released per unit mass of combustible decreases. The presence of air activates the oxidative thermal degradation of the fuel [27]. For open baskets, Fig. 11 shows that the higher the air supply, the higher the mass loss rate. 


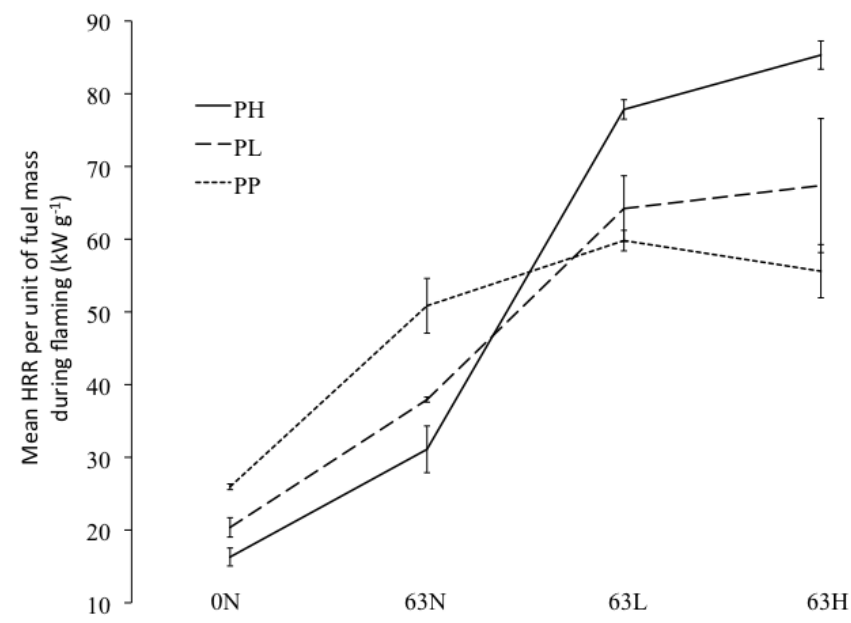

Fig. 9. Mean HRR per unit of fuel mass during combustion for the three species, $K=1.5 \times 10^{-7} \mathrm{~m}^{2}$.

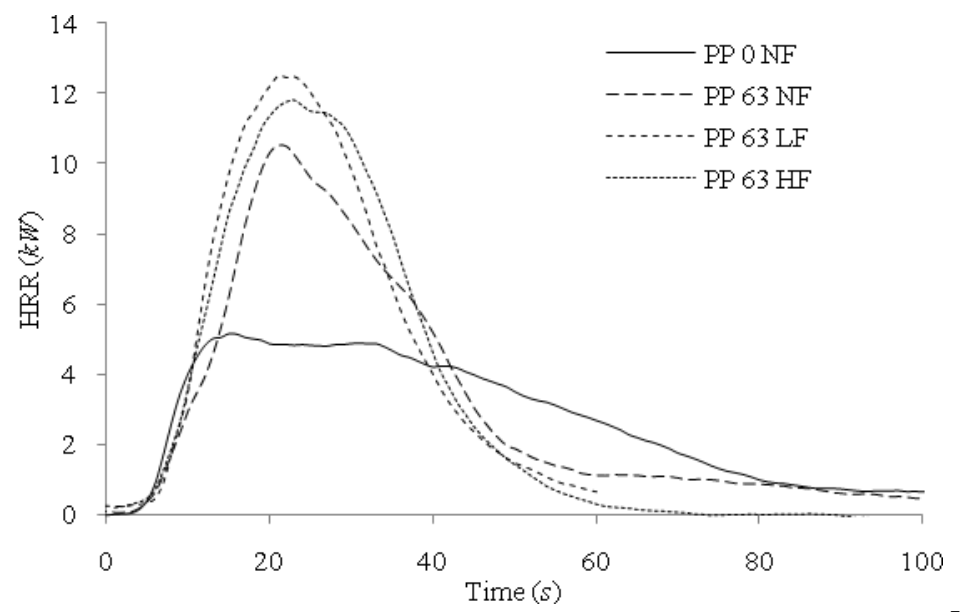

Fig. 10. HRR for Pinus pinaster as a function of the flow, $K=1.5 \times 10^{-7} \mathrm{~m}^{2}$.

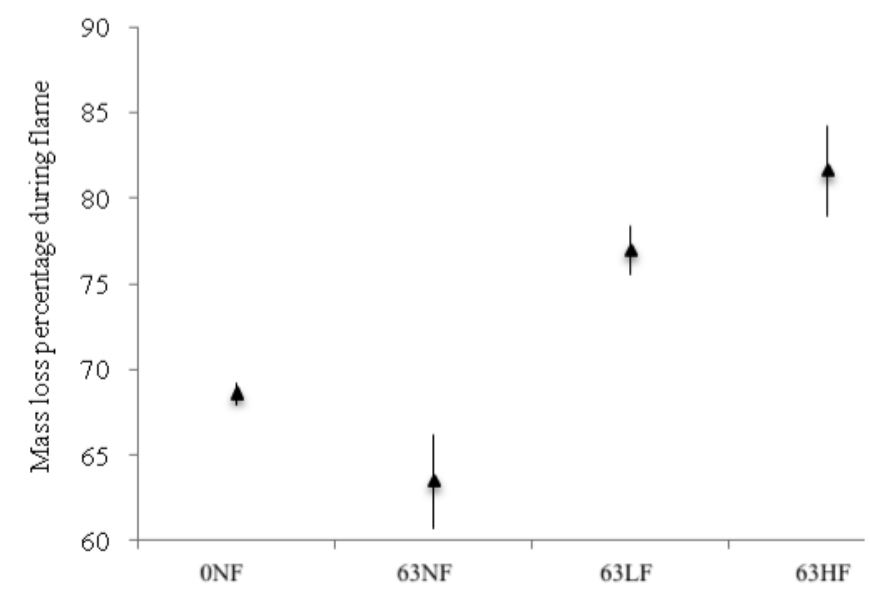

Figure 11. Mass loss during combustion as a function of the flow for Pinus pinaster, $K=1.5 \times 10^{-7} \mathrm{~m}^{2}$.

Two different regimes can occur: inert thermal degradation under the flame front with the closed basket and oxidative thermal degradation when the oxygen supply is sufficient inside the porous fuel bed. For the open basket, from the no-flow condition to low flow condition, the HRR increase follows the mass loss rate 
but the effect is less pronounced than for Pinus halepensis (see Fig. 5). Under high flow conditions, the HRR decreases slightly and the mass loss during combustion increases (see Fig. 11). It seems that the oxygen supply is already sufficient with the low flow and that increasing the flow slows down the reaction. As no significant changes have been noticed in $\mathrm{CO}, \mathrm{CO}_{2}$ or soot production between low flow and high flow conditions, this result is not attributed to a change in combustion regime. It could be due to a change in the pyrolysis process under high flow conditions due to the increased presence of air. It could be also due to the thickness of the needles (low surface-to-volume ratio) and the low contact surface available for heterogeneous reactions compared to the other species. This effect needs to be further investigated in the future.

\section{CONCLUSIONS}

This study demonstrates that permeability is one of the main parameters driving the burning dynamics of porous fuel beds. The energy released during the flaming combustion of a forest floor fuel bed will increase with its permeability. Another important bulk property is the free mean path of radiation. The improvement of the HRR calculation by using the fuel composition allowed accurate results to be obtained and the discrimination of the species. The study has also shown that, for a given permeability, the fuel species have an influence on the HRR but this influence seems to be mainly due to the physical properties of the fuels and not the chemical properties as the fuels have very similar lower heating values. Only Pinus pinaster displays a different behavior which could be fuel specific and needs to be investigated further. The description of the burning dynamics cannot rely only on mean quantities and the HRR is one of the most important factors in allowing an understanding of the driving processes. In the future, the HRR needs to be quantified as a function of permeability and mean path of radiation. In order to obtain accurate trends, it will be necessary to measure the mean path of radiation instead of estimating it by Eq. 8 .

\section{REFERENCES}

[1] Cohen, J.D., Finney, M.A., and Yedinak, K.M., "Active spreading crown fire characteristics: implications for modeling," Proceedings of the Fifth International Conference on Forest Fire Research, D X Viegas Ed., 2006, CD-ROM.

[2] Janssens, M.L., (1991) Measuring rate of heat release by oxygen consumption, Fire Technology 27(3): 234-249. http://dx.doi.org/10.1007/BF01038449

[3] Babrauskas, V., and Peacock, R.D., (1992) Heat release rate: the single most important variable in fire hazard, Fire Safety Journal 18: 255-292. http://dx.doi.org/10.1016/0379-7112(92)90019-9

[4] Byram, G.M., "Combustion of forest fuels," Forest Fire Control and Use, Davis K.P. (ed.), McGraw-Hill Book Company, New York, 1959, p. 61-89.

[5] Alexander, M.E., (1982) Calculating and interpreting forest fire intensities. Canadian Journal of Botany 60: 349-57. http://dx.doi.org/10.1139/b82-048

[6] Finney, M.A., "FARSITE: Fire area simulator - model development and evaluation," USDA, Forest Service, Rocky Mountains Research Station, Research Paper RMRS-RP-4, Ogden, Utah, 1998, $47 \mathrm{p}$.

[7] Schemel, C., Simeoni, A., Biteau, H., Rivera, J., and Torero, J.L., (2008) A calorimetric study of wildland fuels, Experimental Thermal and Fluid Science 32(7): 1381-1389. http://dx.doi.org/ $\underline{10.1016 / j . e x p t h e r m f l u s c i .2007 .11 .011}$

[8] Bartoli, P., Simeoni, A., Biteau, H., Torero, J.L., and Santoni, P.A., (2011) Determination of the main parameters influencing forest fuel combustion dynamics, Fire Safety Journal 46(1-2): 27-33. http://dx.doi.org/10.1016/j.firesaf.2010.05.002

[9] Thomas, P.H., (1976) Some aspects of the growth and spread of fire in the open, Forestry 40: 139164.

[10] Fire Tests - Reaction to Fire - Part 1: Rate of Heat Release from Building Products (Cone Calorimeter), ISO 5660, International Standards Organization, Geneva, 1993. 
[11] Moro, C., "Détermination des caractéristiques physiques de particules de quelques espèces forestières méditerranéennes," INRA report PIF2006-06, Avignon, France, 2006.

[12] Tihay, V., Santoni, P.A., Simeoni, A., Garo, J.P., and Vantelon, J.P., (2009) Skeletal and global mechanisms for the combustion of gases released by crushed forest fuels, Combustion and Flame 156: 1565-1575. http://dx.doi.org/10.1016/j.combustflame.2009.05.004

[13] Grishin, A.M., Mathematical modeling of forest fires and new methods of fighting them, Albini F.A. (ed.), Tomsk State University, Tomsk, Russia, 1997, 390 p.

[14] Pereira, J.M.C., Sequeira, N.M.S., and Carreiras, J.M.B., (1995) Structural Properties and Dimensional Relations of Some Mediterranean Shrub Fuels, International Journal of Wildland Fire 5(1), 35-42. http://dx.doi.org/ 10.1071/WF9950035

[15] Kaviany, M., Principles of Heat Transfer in Porous Media ( $2^{\text {nd }}$ ed.), Springer, New York, 1995, p. 28.

[16] Mendes-Lopes, J.M.C., and Ventura, J.M.P., "Flame characteristics in fires propagating in beds of Pinus halepensis needles," Proceedings of the Fifth International Conference on Forest Fire Research, D X Viegas Ed., 2006, CD-ROM.

[17] Standard Test Method for Measurement of Synthetic Material Flammability Using a Fire Propagation Apparatus, ASTM, E2058-03, 2003.

[18] Morandini, F., Simeoni, A., Santoni, P.A., and Balbi, J.H., (2005) A model for the spread of fire across a fuel bed incorporating the effects of wind and slope, Combustion Science and Technology 177: 1381-1418. http://dx.doi.org/10.1080/00102200590950520

[19] Huggett, C., (1980) Estimation of rate of heat release by means of oxygen consumption measurements, Fire and Materials 12: 61-65. http://dx.doi.org/10.1002/fam.810040202

[20] Brohez, S., (2005) Uncertainty analysis of heat release rate measurement from oxygen consumption calorimetry, Fire and Materials 29: 383-394. http://dx.doi.org/10.1002/fam.895

[21] Taylor, J.R., An Introduction to Error Analysis ( $\left.2^{\text {nd }} e d\right)$, University Sciences Books, Sausalito, CA, 1997, p.75.

[22] Enright, P.A., and Fleischmann, C.M., (1999) Uncertainty of Heat Release Rate Calculation of the ISO5660-1 Cone Calorimeter Standard Test Method, Fire Technology 35(2): 153-169. http://dx.doi.org/10.1023/A:1015416005888

[23] Biteau, H., Steinhaus, T., Schemel, C., Simeoni, A., Marlair, G., Bal, N. and Torero, J.L., 2009. Calculation Methods for the Heat Release Rate of Materials of Unknown Composition. Fire Safety Science 9: 1165-1176. http://dx.doi.org/10.3801/IAFSS.FSS.9-1165

[24] Leroy, V., Cancellieri, D., and Leoni, E., (2006) Thermal degradation of ligno-cellulosic fuels: DSC and TGA studies, Thermochimica Acta 451: 131-138. http://dx.doi.org/10.1016/ j.tca.2006.09.017

[25] De Mestre, N.J., Catchpole, E.A., and Anderson, D.H., (1989) Uniform propagation of a planar fire front without wind, Combustion Science and Technology 65: 231-244. http://dx.doi.org/ 10.1080/00102208908924051

[26] Vaz, G.C., André, J.C.S., and Viegas D.X. (2004) Estimation of the Radiation Extinction Coefficient of Natural Fuel Beds, International Journal of Wildland Fire 13: 65-71. http://dx.doi.org/10.1071/WF03009

[27] Orfao, J.J.M., Antunes, F.J.A., and Figueiredo, J.L. (1999) Pyrolysis kinetics of lignocellulosic materials—-three independent reactions model, Fuel 78: 349-358. http://dx.doi.org/10.1016/S0016$\underline{2361(98) 00156-2}$ 